\title{
Interspecific variation of tree root architecture in a temperate agroforestry system characterized using ground-penetrating radar
}

\author{
Kira A. Borden, Sean C. Thomas \& Marney E. Isaac
}

Version Accepted Manuscript

Citation Borden, K.A., Thomas, S.C. \& Isaac, M.E. Interspecific variation of tree root architecture (published in a temperate agroforestry system characterized using ground-penetrating radar. Plant version) Soil 410, 323-334 (2017). https://doi.org/10.1007/s11104-016-3015-x

Publisher's Subject to Springer Nature's AM terms of use. Statement

How to cite TSpace items

Always cite the published version, so the author(s) will receive recognition through services that track citation counts, e.g. Scopus. If you need to cite the page number of the author manuscript from TSpace because you cannot access the published version, then cite the TSpace version in addition to the published version using the permanent URI (handle) found on the record page.

This article was made openly accessible by $U$ of $T$ Faculty.

Please tell us how this access benefits you. Your story matters. 
6 Interspecific variation of tree root architecture in a temperate agroforestry system characterized using ground-penetrating radar

8 Running Title: Tree root distributions in agroecosystems Kira A. Borden ${ }^{1,2}$, Sean C. Thomas ${ }^{1}$, and Marney E. Isaac*2,3

11

$15{ }^{1}$ Faculty of Forestry, University of Toronto, 33 Willcocks Street, Toronto, ON, M5S 3B3, 16 Canada

17 2Department of Geography \& Planning, University of Toronto, 100 St. George Street, 18 Toronto, ON, M5S 3G3, Canada

$19{ }^{3}$ Department of Physical \& Environmental Sciences, University of Toronto Scarborough,

201065 Military Trail, Toronto, ON, M1C 1A4, Canada

21 Correspondence:

22 Marney E. Isaac

23 marney.isaac@utoronto.ca 


\section{Keywords}

26 Alley cropping; coarse roots; fine root density; root distribution; rooting depth; tree-based

27 intercropping

29 Abstract

31 Background and Aims: Root system architecture regulates belowground access to soil

32 resources. Variation in root architecture is important in agroforestry systems given

33 management objectives to optimize resource acquisition between trees and crops.

34 However, the distributions of live tree roots in agroforestry systems remain understudied

35 due to methodological constraints. In this study, we used ground-penetrating radar (GPR)

36 to describe variation in whole-plant root architecture among tree species at the same

37 agricultural site, with a specific focus on vertical coarse and fine root distributions within

38 the zone of competition with neighbouring crops.

39 Methods: Using GPR, we detected coarse roots of five trees species (Quercus rubra L.,

40 Juglans nigra L., Populus deltoides $\times$ nigra DN177, Picea abies (L.) Karst, and Thuja

41 occidentalis L.) at a tree-based intercropping system in southern Ontario, Canada. A

42 subset of soil profiles were assessed for GPR accuracy. A cumulative root distribution

43 function was used to estimate the rooting depth (D95) of coarse roots. We also measured

44 tree coarse root distributions and fine root density distributions $2 \mathrm{~m}$ into the crop rows, in

45 the zone of competition. 
46 Results: GPR accurately detected approximately $58 \%$ of coarse roots for each study tree.

47 Coarse root architecture varied among species, with differences in $\mathrm{D}_{95}$ and rooting

48 patterns. Fine root length density distribution also varied among species, but was

49 consistently high at 0.10 and $0.20 \mathrm{~m}$ depths regardless of species.

50 Conclusions: Our results suggest differential tree suitability for minimizing belowground

51 competition with crops. Additionally, we illustrate the viability of GPR to characterize

52 vertical profiles of live tree root systems, which is critical for improving our

53 understanding of whole-plant functional traits and belowground plant interactions.

\section{Introduction}

57 Tree root traits influence ecosystem function (Pérez-Harguindeguy et al. 2013; Bardgett

58 et al. 2014; Prieto et al. 2015). Tree root vertical distributions indicate the zone of

59 belowground biophysical processes, while the density of fine roots is closely related to

60 soil resource acquisition (Livesley et al. 2000; Bardgett et al. 2014). These architectural

61 roots traits are increasingly incorporated in both ecosystem and agronomic models. For

62 instance, rooting depth (e.g. D95; the depth to which $95 \%$ of the root system is located) is

63 commonly used in biogeochemical models that describe hydrologic fluxes and carbon

64 budgets at the whole-plant and landscape scales (Warren et al. 2015). Vertical root

65 distributions are uniquely important to tree-based intercropping (TBI), or alley cropping,

66 systems. The presence and function of trees in TBI systems can modify temperature and

67 soil moisture regimes (Clinch et al. 2009), nitrogen (N) fluxes (Isaac et al. 2014) and 
68 biological $\mathrm{N}$ fixation (Nasielski et al. 2015), thus improving nutrient cycles and resource-

69 use efficiency (Thevathasan and Gordon 2004).

71 These regulating effects and efficiencies are commonly ascribed to complementary soil

72 resource use and more complete soil resource exploitation via niche separation through

73 root stratification of tree and crop root systems (Cannell et al. 1996). The vertical

74 distribution of roots is related to depth-dependent processes occurring in the soil profile.

75 Variation in root system structure as a response to resource availability and/or the

76 presence of competing plants is a dominant mechanism for minimizing competition

77 (Casper and Jackson 1997; Malamy 2005). In this regard, tree root architecture is a key

78 determinant of complementary resource use with adjacent crops (Ong et al. 1991; Schroth

79 1999; Schwendenmann et al. 2010). As an added benefit, tree roots that are vertically

80 stratified with crop roots can access nutrients leached below the crop roots, thereby

81 reducing nutrient run-off (Van Noordwijk and Purnomosidhi 1995; Dougherty et al.

82 2009; Bergeron et al. 2011), and can input organic matter deeper in soil, sustaining soil

83 carbon pools (Bambrick et al. 2010; Upson and Burgess 2013). To optimize the benefits

84 from TBI systems, it is generally desirable that tree species should feature deep tree root

85 systems that are vertically stratified with neighbouring crops.

86

87 Despite the need to quantify tree root architecture in TBI systems, only a few studies

88 have examined live tree roots in situ. In these instances, researchers generally employ

89 destructive or semi-destructive root study methods such as measuring roots that are

90 exposed in a trench wall (e.g. Upson and Burgess 2013; Cardinael et al. 2015), visualized 
91 using minirhizotons (e.g. Jose et al. 2001), extracted from soil cores (e.g. Upson and

92 Burgess 2013), and/or, less commonly, excavated (e.g. Jose et al. 2001; Das and

93 Chaturvedi 2008). These studies generally differentiate between structural coarse roots

94 (typically $>2 \mathrm{~mm}$ in diameter) and absorptive fine roots (typically $<2 \mathrm{~mm}$ ) and often

95 describe the root system architecture in terms of relative depth in the soil profile. Since

96 roots are generally concentrated near the surface and their prevalence decreases with

97 depth, empirical models that capture this trend are useful for comparative purposes and

98 for calculating the proportion of roots at given depths (Gale and Grigal 1987; Jackson et

99 al. 1996; Gwenzi et al. 2011). However, destructive sampling methods are not repeatable

100 at the same location, only a portion of the root system is measured, and large amounts of

101 root data are challenging to collect. Therefore, alternative approaches to destructive

102 sampling are appealing (Jayawickreme et al. 2013).

103

104 Ground-penetrating radar (GPR) is a geo-imaging technology that can rapidly collect

105 subsurface data while largely avoiding disturbance to root systems (Stokes et al. 2002;

106 Guo et al. 2013; Jayawickreme et al. 2013). In-field experiments have used GPR to

107 describe the vertical distribution of coarse root systems in terms of biomass with depth of

108 Quercus douglasii (Raz-Yaseef et al. 2013), and rooting density with depth in studies of

109 Castanopsis eyrei and Schima superb (Yan et al. 2013) and Theobroma cacao and

110 Terminalia ivorensis (Isaac and Anglaaere 2013; Isaac et al. 2014). Radar signals emitted

111 from GPR can be reflected at the root-soil interface due to a difference in dielectric

112 permittivity caused by higher water content within the coarse root compared to the soil

113 (Barton and Montagu 2004; Dannoura et al. 2008; Hirano et al. 2009). As the GPR device 
114 is moved on the surface, sequential emissions and their resulting reflected radar signals

115 are compiled into an interpretation of the subsurface (geo-image). Generally, coarse roots

116 greater than $0.5 \mathrm{~cm}$ in diameter and orientated between $45^{\circ}$ and $135^{\circ}$ from the plane of

117 the GPR path can be detected and will induce a hyperbolic reflection visualized in the

118 geo-image (Barton and Montagu 2004; Guo et al. 2013; Guo et al. 2015). These root

119 reflections are identified across multiple geo-images to identify coarse root distribution

120 (Isaac and Anglaaere 2013; Isaac et al. 2014; Wu et al. 2014).

122 The objective of the present study was to describe and compare architectural roots traits

123 that underlie ecosystem function and complementary interactions in an agroforestry

124 system. To do this, we examined the root systems of five temperate tree species in a TBI

125 system in southern Ontario, Canada, using GPR and a commonly used empirical

126 distribution function to describe the vertical distribution of coarse roots to a depth of $1 \mathrm{~m}$.

127 We paid special attention to tree root distributions in the crop row to assess the zone of

128 competition with neighbouring crops. In this zone of competition, we supplemented the

129 structural root data (coarse roots detected by GPR) with measurements of fine root

130 distributions (undetectable by GPR) based on soil cores. We hypothesized that given

131 suitable soil and root conditions, GPR would provide an accurate detection of coarse root

132 vertical distributions among tree species. We also hypothesized that detected vertical root

133 distributions will vary among the tree species at the same agricultural site due to intrinsic

134 growth characteristics of the species in question, and that coarse root distributions

135 correlate with fine root density. These differences in architectural traits could be used to

136 inform species selection and management strategies in temperate TBI systems. 


\section{Materials and Methods}

142 Ground-penetrating radar geo-imagery and physical soil and root samples were collected 143 at the University of Guelph Agroforestry Research Station (44³2'28' N, 80¹2'32” W)

144 between April and July, 2012. Elevation at the site is $325 \mathrm{~m}$ and the mean annual 145 precipitation is $830 \mathrm{~mm}$ (Oelbermann and Voroney 2007). The research plot was 146 established in 1987 as a TBI experimental site with tree species planted in a randomized

147 block design. Our study examined root systems of 13 individual trees representative of 5 148 tree species: Juglans nigra L. (black walnut; $\mathrm{DBH}=24.4 \pm 1.2 \mathrm{~cm}($ mean \pm S.E. $) ; n=3)$,

149 Picea abies (L.) Karst (Norway spruce; $\mathrm{DBH}=21.45 \pm 3.5 \mathrm{~cm} ; n=2$ ), Populus deltoides $150 \times$ nigra $\mathrm{DN} 177$ (hybrid poplar; $\mathrm{DBH}=33.5 \pm 0.6 \mathrm{~cm} ; n=2)$, Quercus rubra L. (red oak;

$151 \mathrm{DBH}=21.8 \pm 0.3 \mathrm{~cm} ; n=3$ ) and Thuja occidentalis $\mathrm{L}$. (eastern white cedar; $\mathrm{DBH}=7.5$

$152 \pm 0.5 \mathrm{~cm} ; n=3)$. Species selection was based on trees common in agroforestry systems in 153 southern Ontario. Study trees were chosen from randomly selected blocks and with the

154 requirement that the tree was located on flat soil, had neighbouring trees of the same 155 species, and was assessed to be of representative size for that species at the site. The 25156 year-old study trees were planted $6 \mathrm{~m}$ apart in the tree rows (except $T$. occidentalis with

157 1-m spacing), and intercropped with crop rows $15 \mathrm{~m}$ wide. Zea mays L. (maize), Glycine $158 \max$ L. Merr (soybean), Triticum aestivum L. (winter wheat) were grown in crop rows 159 following conventional crop rotations of the region and under no-till cultivation since 
1601996 (Wotherspoon et al. 2014). The soil is Grey-Brown Luvisol with a sandy-loam

161 texture (65\% sand, $25 \%$ silt, and $10 \%$ clay) (Oelbermann \& Voroney 2007). A moraine

162 horizon occurs approximately $1 \mathrm{~m}$ below the surface.

163

\section{adar studby of coarse roots}

166 Geo-images were collected in a grid $(4.5 \times 4.5 \mathrm{~m})$ centred on the base of the tree stem

167 and aligned orthogonally with the tree and crop rows (Fig. 1). Rope attached to opposing

168 sides of frame guided the GPR unit in straight and square transects that were spaced 10

$169 \mathrm{~cm}$ apart, which equated to 92 GPR transects within each survey area. Geo-images were

170 collected between April and July 2012 using a GPR unit with a centre frequency of 1000

171 MHz (NogginPlus; Sensors and Software Inc., Mississauga, ON, Canada), which was

172 selected to maximize both the resolution of coarse roots (to diameters of $0.5 \mathrm{~cm}$ ) and the

173 depth of signal penetration (to depths of 50 to $100 \mathrm{~cm}$ ) (Guo et al. 2013). The average

174 signal velocities were calculated from signal travel time to metal rods at known depths.

175 These were measured on the same day of data collection and signal velocity ranged

176 between 0.08 and $0.1 \mathrm{~m} \mathrm{~ns}^{-1}$. Volumetric root water concentration was $76 \%$ and

177 volumetric soil water concentration was $12 \%$ (Borden et al. 2014) meeting a contrast

178 requirement for radar signal reflection (Hirano et al. 2009).

180 Prior to geo-image analysis, non-root anomalies (e.g. horizontal reflections and signal

181 noise) were minimized by applying a sequence of processing steps (DC shift, dewow,

182 background removal). A spreading and exponential gain filter (SEC2) was applied to 
183 enhance delineation of reflection patterns with depth (EKKO_View Deluxe; Sensors \&

184 Software). We maximized the distance between individual trees of the same species at the

185 site, though it is possible a nominal amount of roots from neighbouring trees were

186 measured. Root reflections were visually identified in all geo-images and reflection

187 locations recorded using EKKO_Interp (Sensors \& Software).

189 To assess the level of accuracy of GPR coarse root detection, root locations were

190 compared to identified root reflections in the geo-images. These comparisons were made

191 from a subset of soil profiles ( $1.0 \mathrm{~m}$ wide $\times 0.7 \mathrm{~m}$ deep) exposed near each tree and

192 matched to GPR transect locations and randomly located at $1,1.5$, or $2.0 \mathrm{~m}$ from the tree

193 (Fig. 1). A positive detection was confirmed when a coarse root was found within $0.10 \mathrm{~m}$

194 of detection location, the approximate resolution of the study, and within the detectable

195 angle range of $45^{\circ}$ and $135^{\circ}$ from the soil profile. We measured the diameter of each root

196 and the depth of the root to the soil surface. When one detected coarse root matched with

197 multiple roots, the largest diameter root was assumed as the positive detection and the

198 smaller diameter root(s) as missed detection(s). When no root was found where an

199 identified reflection was observed in the geo-image, a false detection was recorded.

\section{oot distributions}

203 GPR signal attenuation depends upon the frequency of the GPR unit and the soil

204 conditions. During our study, radar signal attenuation occurred approximately $0.70 \mathrm{~m}$

205 below the surface. On sandy soils co-dominated by Quercus myrtifolia and Quercus 
geminata, Day et al. (2013) applied GPR detected coarse root biomass estimates to a site-

207 and species-specific cumulative curve to account for the relatively small portion of root

208 biomass located between 60 and $100 \mathrm{~cm}$, which was beyond the detectable range of GPR

209 at that site. Similarly, we apply a commonly used root distribution model to extrapolate a

210 fraction of roots to depths beyond that of the maximum detectable roots. The model used

211 was described by Gale and Grigal (1987) and Jackson et al. (1996):

$$
Y=1-\beta^{D}
$$

213 where $\mathrm{Y}$ is the cumulative proportion of roots at depth (D) and $\beta$ is the fitted extinction

214 coefficient. Equation 1 assumes there is an asymptotic increase of roots cumulatively

215 with depth and was fitted to detected coarse root data that were pooled in $0.10 \mathrm{~m}$ depth

216 intervals. The depth to which $95 \%$ of the roots are located (D95), used as a measure of

217 rooting depth but is not the maximum rooting depth, was calculated using equation 1.

219 We assumed that roots growing into the crop rows would have the greatest effect on crop

220 root access to soil resources. Therefore, coarse root detections that occurred within the

221 crop rows were separately analyzed for their distribution. Within this zone of competition

222 (Fig. 1), root length per unit soil volume was measured as the architectural trait of the

223 fine, absorptive roots, providing an indicator of soil exploration by fine roots with depth

224 (Pérez-Harguindeguy et al. 2013). Fine roots were collected using soil cores $(5 \mathrm{~cm}$

225 diameter) sampled at four depths, $0.10,0.20,0.40$, and $0.60 \mathrm{~m}$, from exposed soil profiles

226 in the zone of competition (1.0, 1.5, and $2.0 \mathrm{~m}$ from the tree stem) (Fig. 1). Fine roots

227 were extracted following Livesley et al. (1999). Dead roots were omitted, characterized

228 by a loss of plasticity and change in colour (dead roots were often very dark). Soil 
229 samples were collected prior to the germination of soybean crops, to limit sampling to

230 tree fine roots in the crop rows. The exception was for T. occidentalis which was sampled

231 last; in this case soybean roots were differentiated as very light in colour and with

232 distinctive morphology (e.g. with nodules) from the fine roots of T. occidentalis. Fine

233 roots were placed in deionized water and scanned using a flatbed scanner at 600 dpi and

234 measured for length (WinRHIZO; Regents Instruments, Montreal, Canada). Fine root

235 length density (FRLD; $\mathrm{cm} \mathrm{cm}^{-3}$ ) was calculated as the ratio of the length of fine roots to

236 the volume of soil (soil core volume of $100 \mathrm{~cm}^{3}$ ). Additionally, a morphological trait,

237 specific root length (SRL; $\mathrm{m} \mathrm{g}^{-1}$ ), was also calculated as the ratio of total root length by

238 the dry weight mass of roots, which were measured after being dried in an oven at $65{ }^{\circ} \mathrm{C}$

239 for 48 hours. To also evaluate the potential of using GPR for indirectly describing fine

240 root distribution by proxy of coarse root detections, the number of coarse roots detected

241 by GPR were compared to the FRLD at matched depths and study trees.

\section{tatisticabanalysis}

245 Statistical analysis was completed in R version 3.2.4 (R Foundation for Statistical

246 Computing, Vienna, Austria) and the level of significance was set at $p<0.05$. GPR

247 accuracy was calculated as the proportion of correctly identified coarse roots relative to

248 the total number of exposed coarse roots. Logistic regression tested for the effects of root

249 diameter, root depth, and species on GPR detection accuracy $(1=$ detected, $0=$ not

250 detected). For the correlation between GPR-detected coarse roots and FRLD, the inherent

251 variability of different sampling depths on FRLD was assessed using linear regressions 
252 which tested for main and interactive effects. Analysis of variance (ANOVA) was

253 completed for each summary statistic (mean depth and skewness of the detected coarse

254 roots) across the five species and, when significant, this analysis was followed by

255 Tukey's HSD for pairwise comparisons. Larger positive skewness describes a higher

256 concentration of detected roots nearer the surface and a tail of detected roots with

257 increasing depth, while a skewness value closer to 0 indicates symmetrical distribution of

258 root depths. Parametric assumptions of normality and equal variance were met, based on

259 graphical analyses and the Shapiro-Wilk test. When data did not meet parametric

260 assumptions, Kruskal-Wallis test and post hoc test from the agricolae package was used

261 to test for variation among groups, specifically for differences among species or sampling

262 distances and depths for FRLD and GPR accuracy data.

263

264 Results

265

\section{PR root detection accuracy}

268 The locations of 89 coarse roots were correctly identified in the subset of GPR geo-

269 images of a total of 160 actual coarse root locations (true positives) in matched soil

270 profiles. The level of accuracy per study tree was $57.9 \pm 3.7 \%$ (mean \pm S.E.; $n=13$ ) and

271 when false positives were included was $48.1 \pm 3.6 \%(n=13)$. The number of false

272 positives occurred relatively evenly through the soil profile and did not vary significantly

273 among depth intervals determined from the non-parametric Kruskal-Wallis test ( $p=$

274 0.69), and were thus assumed to have a marginal effect on estimates of relative coarse 
275 root distributions. Logistic regression of GPR detections and missed detections indicated

276 significant differences in detection accuracy related to root depth $(p=0.012)$ and root

277 diameter $(p<0.001)$. To illustrate, in the top $0.50 \mathrm{~m}$ of soil the accuracy of coarse root

278 detection was $60.3 \pm 3.6 \%(n=13)$ opposed to an accuracy of $35.2 \pm 14.8 \%(n=9)$ for

279 coarse roots between 0.50 and $0.70 \mathrm{~m}$ depths. Larger coarse roots $(\geq 1 \mathrm{~cm})$ were more

280 successfully detected by GPR with an accuracy of $83.5 \pm 5.8 \%(n=12)$, opposed to an

281 accuracy of $49.8 \pm 4.8 \%(n=13)$ for small coarse roots $(<1 \mathrm{~cm})$. Once root size and

282 depth effects were accounted for, there were no significant effects of tree species in

283 logistic regression analyses.

284

285 Fine roots are assumed to be undetectable by GPR. As an indirect method of detecting

286 fine roots, we found that the number of coarse roots detected by GPR explained only $11 \%$

287 of the variation of FRLD $(n=52 ; p=0.02)$. However, root distribution is a highly depth-

288 dependent process and sampling depth was found to be a strong predictor of FRLD $\left(r^{2}=\right.$

$2890.55 ; p<0.001)$. Furthermore, including both depth and coarse root quantity as predictors

290 revealed a significant main effect of depth only $(p<0.001)$, with no significant

291 interaction effect (depth $\times$ coarse roots) $(p>0.05)$.

292

\section{/hole plantb coarse root architecture}

295 The vertical distribution of coarse roots showed significant variation among species in

296 terms of the mean depth of detected coarse roots $(p=0.009$; Table 1). Skewness

297 measures showed no significant differences among species, but ranged from $0.21 \pm 0.16$ 
298 for J. nigra and $0.68 \pm 0.19$ for Populus sp. (Table 1). Fitted $\beta$ values were calculated

299 from equation 1 using species' means of pooled detected coarse roots in $0.10 \mathrm{~m}$ depth

300 increments. The rooting depth at which $95 \%$ of roots are located (i.e. D95) of all species

301 ranged between 0.52 and $0.95 \mathrm{~m}$ (Table 1$)$.

302

303 Of the deciduous species, Populus sp. had a shallower coarse root distribution with a

304 mean detected coarse root depth of $0.22 \pm 0.01 \mathrm{~m}$ and a lower $\beta(0.958)$ leading to a $\mathrm{D}_{95}$

305 of $0.70 \mathrm{~m}$ (Table 1). The coarse roots of $P$. abies followed a similar vertical distribution

306 pattern to Populus sp. in terms of mean detected coarse root depths $(0.21 \pm 0.02 \mathrm{~m})$ and

307 D95 (0.70 m) (Table 1). However, P. abies had a slightly more symmetric distribution,

308 indicated by a lower skewness $(0.43 \pm 0.08)$ (Table 1$)$. There was a prominence of coarse

309 roots (approximately $67 \%$ ) between 0.10 and $0.30 \mathrm{~m}$ for both $P$. abies and Populus sp.

310 (Fig. 2). Q. rubra and J. nigra had a lower dominant zone of coarse roots which was less

311 pronounced, with 53 and $55 \%$, respectively, of coarse roots located between 0.20 and

$3120.40 \mathrm{~m}$ (Fig. 2). J. nigra and Q. rubra had the deepest root systems with mean detected

313 root depths of $0.29 \pm 0.01$ and $0.29 \pm 0.02 \mathrm{~m}$ and $\mathrm{D} 95$ of $0.95 \mathrm{~m}$ (Table 1). T. occidentalis

314 was distinctly the most shallow-rooted tree species with a mean detected coarse root

315 depth of $0.17 \pm 0.02 \mathrm{~m}$ and a $\mathrm{D}_{95}$ of $0.52 \mathrm{~m}$ (Table 1). Its high skewness $(0.65 \pm 0.15$;

316 Table 1) indicates a high concentration of roots near the soil surface, specifically there

317 was a high proportion of coarse roots (45\%) detected between 0.10 and $0.20 \mathrm{~m}$ (Fig. 2). 318

\section{oarse andfine root distribution in the zone of competition}


321 In the crop rows, the mean depth of detected coarse roots varied among tree species, but

322 only the mean depths of detected coarse roots of T. occidentalis and J. nigra were

323 significantly $(p=0.031)$ different at $0.18 \pm 0.03$ and $0.30 \pm 0.02 \mathrm{~m}$ respectively (Table

324 2). J. nigra and Q. rubra had the deepest detected coarse roots in the zone of competition

325 with a mean depth of detected coarse roots of $0.30 \pm 0.02$ and $0.27 \pm 0.03 \mathrm{~m}$, respectively

326 (Table 2). The deeper root profiles for these two species led to a higher $\beta(0.969$ and

3270.963 , respectively) and deeper $\mathrm{D}_{95}(0.95$ and $0.80 \mathrm{~m}$, respectively) (Table 2). The coarse

328 roots of Populus sp. and P. abies were moderately deep in the crop rows, with a D95 of

3290.74 and $0.66 \mathrm{~m}$, respectively (Table 2). D95 of coarse roots in the zone of competition

330 (Table 2) closely matched D95 values for the entire tree (Table 1), with less than $10 \mathrm{~cm}$

331 differences. Q. rubra showed the largest divergence in these values; a D95 of $0.82 \mathrm{~m}$ in

332 the zone of competition (Table 2), compared to a $\mathrm{D}_{95}$ of $0.95 \mathrm{~m}$ for the entire coarse root

333 system (Table 1).

335 Fine root densities varied significantly among species at each sampling depth $(p<0.01$;

336 Fig. 3). There was no significant variation of FRLD among sampling distances following 337 a Kruskal-Wallis test $(p>0.05)$. Generally, the highest concentrations of fine roots were

338 found at the $0.10 \mathrm{~m}$ and $0.20 \mathrm{~m}$ sampling depths. P. abies and Populus sp. had the highest

339 FRLD $(2.99 \pm 0.57$ and $2.75 \pm 0.35$ (mean \pm S.E. $) \mathrm{cm} \mathrm{cm}^{-3}$, respectively) at $0.10 \mathrm{~m}$ depth

340 (Fig. 3). FRLD consistently declined with sampling depth for all species. The largest

341 decline in FRLD with increasing depth occurred for $P$. abies with a reduction of FRLD

342 between the 0.20 and $0.40 \mathrm{~m}$ sampling depths of $84 \%$ (Fig. 3). At $0.60 \mathrm{~m}$ depth, Populus

343 sp., Q. rubra, and P. abies had the highest FRLD of $0.56 \pm 0.13,0.33 \pm 0.07$, and $0.24 \pm$ 
$3440.06 \mathrm{~cm} \mathrm{~cm}^{-3}$, respectively (Fig. 3). T. occidentalis had significantly less FRLD than the

345 other species at all sampling depths, except at $0.10 \mathrm{~m}$ (Fig. 3). T. occidentalis also

346 showed significantly lower SRL $\left(21.4 \pm 3.4 \mathrm{~m} \mathrm{~g}^{-1}\right.$; mean \pm S.E. $)$ than the other tree

347 species following significant ANOVA $(p<0.001)$ and Tukey's honest significance test.

348 There were no significant differences of SRL among the other tree species, although $J$.

349 nigra had the highest SRL $\left(69.7 \pm 7.4 \mathrm{~m} \mathrm{~g}^{-1}\right)$ followed by $Q$. rubra, Populus sp., and $P$.

350 abies $\left(55.1 \pm 5.0,51.0 \pm 4.7\right.$, and $46.0 \pm 7.7 \mathrm{~m} \mathrm{~g}^{-1}$, respectively).

352 Discussion

353

\section{lethodological considerations to advance the study of root systems}

356 More than half of the coarse roots in exposed soil profiles were correctly identified by

357 GPR; with improved accuracy for larger coarse roots and roots at shallower depths.

358 Signal resolution dictates that smaller coarse roots are less likely to be detected by GPR

359 than larger coarse roots and radar signal attenuation limits the detection of coarse roots

360 with increasing depth (Butnor et al. 2001; Hirano et al. 2012; Guo et al. 2015). Therefore,

361 given consistent moisture contents and soil texture, inaccuracies in the GPR data can be

362 largely attributed to reduced signal:noise ratio in deeper and smaller roots. In our study,

363 the detection accuracy for coarse roots larger than $1 \mathrm{~cm}$ in diameter was almost twice the

364 level of accuracy for coarse roots less than $1 \mathrm{~cm}$ in diameter. Hirano et al. (2012), in their

365 study of Pinus thunbergii coarse roots on sandy soils in Japan (the only other in-field

366 study to report similar accuracy data), reported a dramatic improvement in detection 
367 accuracy from $6.6 \%$ for coarse roots less than $1 \mathrm{~cm}$ in diameter to $54.4 \%$ for roots larger

368 than $1 \mathrm{~cm}$. Differences in detection frequencies among studies can be attributed to

369 variations in substrate and biotic conditions required for optimal GPR detection of tree

370 roots, and to instrumentation, but also to experimenter bias, as a higher frequency of

371 identified detections might occur simultaneously with an increase in false positives.

372 While advancements have been made towards developing an automated tool to describe

373 coarse root architecture based on GPR data (e.g. Wu et al. 2014; Li et al. 2016), in-field

374 application and root identification still requires supervised analysis steps. As emphasized

375 in other recent studies (e.g., Guo et al. 2015), field-based accuracy assessments will better

376 inform the experimenter of any bias and possible need to compensate during analysis.

378 Since tree root studies rarely sample to the maximum root depth due to methodological

379 challenges, it is also appealing to describe less-accessible roots based on measurable root

380 distributions (Schenk and Jackson 2002). To address the under-representation of deep

381 roots detected by GPR (in this study, those deeper than $0.70 \mathrm{~m}$ ), a root distribution curve

382 was applied to extrapolate the distribution data to lower depths. D95 values calculated

383 during this study were shallower than $1 \mathrm{~m}$ for all species, which supports the assertion

384 that root systems are predominately located in the upper $1 \mathrm{~m}$ of soil (Jackson et al. 1996).

385 While we did not sample to the maximum rooting depth of the study trees in this study,

386 and thus the calculated D $95_{5}$ values might be underestimated, a companion study that

387 completely excavated the same study trees (Borden et al. 2014) observed few roots

388 growing beyond the moraine till located approximately at $1 \mathrm{~m}$ depth. The restrictive

389 subsurface could be a main determinant of rooting depth at this site (Stone and Kalisz 
390 1991). However, when there is a high proportion of deep roots, our approach would not

391 be appropriate for two reasons: i) GPR is limited in detecting deep coarse roots, the depth

392 of which varies according to GPR frequency and site conditions, and ii) the proportion of

393 roots with depth may not follow the cumulative curve (e.g. phreatophytes) (Zhang et al.

394 2013). Complete excavations of deep roots systems in conjunction with GPR assessments

395 would be necessary to fully explore this issue.

396

\section{oarse rootarchitecture of trees in temperate intercropping systems}

399 We found interspecific variation of coarse root architecture among same-aged tree

400 species in a temperate agricultural system. Notably, there were identifiable differences in

401 rooting depth, characterized by $\mathrm{D}_{95}$, and vertical rooting pattern, characterized by relative

402 root distribution, skewness, and the cumulative root curve ( $\beta$ ). If roots are more evenly

403 and deeply distributed in the profile, the cumulative proportion of roots will increase less

404 rapidly with depth and the resultant $\beta$ value will describe a more gradual asymptotic

405 curve (i.e. higher $\beta$ values) (Gale and Grigal 1987; Jackson et al. 1996; Gwenzi et al.

406 2011). In the present study, the shade tolerant $T$. occidentalis had the lowest $\beta$ value, with

407 many superficial coarse roots and high skewness, characteristic of its late-successional

408 and slow-growing status. P. abies and Populus sp. had moderately deep coarse root

409 systems. P. abies is known to have many lateral roots in surface soils (Puhe 2003), and is

410 also associated with late-successional forests. While P. abies is reported to have roots

411 that can grow below $2 \mathrm{~m}$ (Stone and Kalisz 1991; Puhe 2003), with maximum root depth

412 variable according to soil conditions (i.e. texture and moisture levels), on sandy loam 
413 soils it was found that this species had a majority of its roots located in the top $1 \mathrm{~m}$ (Puhe

414 2003). The fast-growing Populus sp. was the largest tree species (at the time of

415 measurement) included in the present study. Populus hybrids generally have extensive

416 lateral root systems, and prolific root systems are documented in agroforestry systems

417 (Mulia and Dupraz 2006; Plante et al. 2014). Populus sp. in this study is a hybrid of the

418 shade-intolerant species Populus deltoides and P. nigra; its early successional status

419 would make rapid and deep root growth advantageous (Gale and Grigal 1987). Although

420 Populus sp. at this study site had deep coarse roots, it also displayed a relatively high

421 concentration of roots near the surface compared to the two other deciduous species.

423 The other deciduous species, J. nigra and Q. rubra, which are shade intolerant and mid-

424 tolerant, respectively, had a prominence of coarse roots at lower depths (between 0.20

425 and $0.40 \mathrm{~m}$ depth). This type of root distribution might be beneficial to access soil

426 resources from various depths earlier in forest succession. Both species are known to

427 have pronounced taproots and had the deepest roots among the study trees. Quercus spp.

428 are known to have particularly deep root systems that can access deep water in xeric

429 environments (Canadell et al. 1996). At a TBI system in Indiana, USA, on silty loam

430 soils, complete excavation of J. nigra and Q. rubra revealed root systems to $0.90 \mathrm{~m}$ (Jose

431 et al. 2001), which is similar to the D95 values reported in our study (0.95 m). Although

432 the trees at the Indiana site were younger (10 years old), they grew in less constrained

433 soils (silt loam subsoil to $\sim 1.75 \mathrm{~m}$ ) (Jose et al. 2001).

434 


\section{ree root distribution and potential competitiveness in a tree-based}

\section{interchopping system}

438 Root studies conducted in TBI or alley cropping systems often target the tree-crop

439 interface and have typically included measures of the absorptive fine roots such as FRLD

440 (e.g. Livesley et al. 2000; Bouttier et al. 2014). In our study, to further assess tree-crop

441 interactions we sampled live tree coarse and fine roots within a 1 to $2 \mathrm{~m}$ zone from the

442 tree rows, an active zone of competition with crops (Thevathasan and Gordon 2004)

443 where suppression of crop yield has been reported (Gillespie et al. 2000; Miller and

444 Pallardy 2001; Thevathasan and Gordon 2004; Reynolds et al. 2007). In this zone of

445 competition, all tree species, except for T. occidentalis, had a D95 that were below 0.60

$446 \mathrm{~m}$, indicating that many deeper lateral roots extended into the crop rows, which might

447 reduce belowground competitive interaction with crops.

449 Despite the presence of deep roots and the potential for complementary acquisition of soil

450 resources with crops, Populus sp. in particular demonstrated high competitive traits in the

451 crop rows: a high concentration of coarse and fine roots in shallow soils (above $0.30 \mathrm{~m}$ ).

452 Mulia and Dupraz (2006) speculated that fast growing Populus euramericana cv. I214,

453 with earlier leaf phenology rapidly colonized surface soils prior to crop growth, when soil

454 moisture in topsoil is still high. In the present study, which is representative of early-

455 season conditions, there was high and relatively consistent FRLD for Populus sp. at 0.10

456 and $0.20 \mathrm{~m}$ sampling depths. At the same study site, Link et al. (2015) using stable

457 isotope analysis $\left(\delta^{18} \mathrm{O}\right)$ found this species acquired soil water predominantly from $0.20 \mathrm{~m}$ 
458 in the soil profile early in the growing season. Interestingly, later in the growing season

459 Populus sp. acquired more water from lower in the soil profile but overall water uptake

460 seemed to occur throughout the soil profile ( 0 to $0.70 \mathrm{~m}$ ) (Link et al. 2015). In response

461 to crop competition, Populus hybrids have shown limited stratified fine root distributions

462 with crop roots within the top $0.30 \mathrm{~m}$ of soil compared to Quercus rubra (Populus

463 deltoides $\times$ nigra DN3333 and DN3570; Bouttier et al. 2014) and compared to Juglans

464 hybrid (Populus euramericana cv. I214; Mulia and Dupraz 2006). More research with

465 higher repetitions is required to assess the degree of intraspecific plasticity for Populus

466 hybrids given shifting resource demands during the crop growing period.

468 Both of the coniferous species examined had relatively high concentration of shallow 469 roots, which would likely increase root overlap with crop rooting zones. Similarly, Plante

470 et al. (2014) showed that $2 \mathrm{~m}$ into the cropping area in a temperate windbreak system fine

471 and coarse roots of Picea abies and P. glauca were predominately located in sandy loam

472 topsoil ( 0 to $0.30 \mathrm{~m}$ ). In a forest study on silt loam soils, $P$. abies fine roots were mainly

473 above $0.30 \mathrm{~m}$ grown in either monoculture or in mixture with a potential competitor

474 (Fagus sylvatica) (Bolte and Villanueva 2006). The smaller and shallow-rooted $T$.

475 occidentalis showed a potentially similar rooting profile to that of herbaceous crops.

476 However, we found this smaller tree species to have a low coarse and fine root density in

477 the crop row in conjunction with low SRL, suggesting a low competitive threat to crops

478 despite its shallow root system.

479 
J. nigra had the deepest coarse roots in the cropping area $\left(\mathrm{D}_{95}=0.98 \mathrm{~m}\right)$ followed by $Q$.

481 rubra $\left(\mathrm{D}_{95}=0.80 \mathrm{~m}\right)$. These two species also had less coarse and fine root density in

482 shallow soils compared to Populus sp. and P. abies. However, the SRL of J. nigra and Q.

483 rubra were higher than for the other species. Link et al. (2015) found that active early

484 growth fine roots of $J$. nigra acquired water at $0.10 \mathrm{~m}$, but that this activity was lower in

485 the soil profile ( 0.40 to $0.70 \mathrm{~m}$ ) later in the season with high crop growth. Variation in

486 root morphological traits (e.g. SRL) can modify resource acquisition patterns in a soil

487 profile, with competitive exclusion potentially inducing root distributions that are more

488 complementary. In southern France on sandy and silty alluvial soils, a Juglans hybrid

489 displayed deeper root systems when grown with durum wheat (Triticum turgidum $\mathrm{L}$.

490 subsp. durum) compared to tree-only stands (Mulia and Dupraz 2006; Cardinael et al.

491 2015). Similarly, on silt loam and clay loam soils the fine root distribution of $Q$. rubra

492 showed a tendency to stratify with adjacent crop roots in the top $0.30 \mathrm{~m}$ of soil (Bouttier

493 et al. 2014). In Indiana, USA, Q. rubra and J. nigra had a high density of roots at similar

494 depths as the adjacent crops, specifically above $0.30 \mathrm{~m}$ (Jose et al. 2001); however, root

495 distribution was not differentiated within that depth class $(0$ to $0.30 \mathrm{~m})$, where some

496 stratification of roots could occur. The results from our study showed differences in

497 coarse and fine root distributions among the study species within the 0 to $0.30 \mathrm{~m}$ soil

498 depth, which could correspond to important differences for shared soil resources with

499 crops.

500

501 Conclusions

502 
503 We used a combination of physical and non-destructive sampling to describe tree root

504 architectural traits. We found interspecific variation of temperate tree root depth and

505 distribution under herbaceous crop cultivation on sandy loam soils. A Populus hybrid and

506 Picea abies showed more competitive architectural root traits, while Juglans nigra and

507 Quercus rubra showed more complementary root distribution patterns in association with

508 crops. Quantifying tree rooting patterns of relevance to management objectives can be

509 useful in species selection for TBI systems. More research is required to discern

510 intraspecific plasticity of belowground tree root traits over time and to determine the

511 effect of cultivation practices on tree root system architecture. Describing belowground

512 architecture in species- and context-specific terms can better capture functional

513 differences associated with vegetative structure in TBI systems.

\section{Acknowledgements}

516 We would like to thank Dr. Naresh Thevathasan and Dr. Andrew Gordon at the

517 University of Guelph Agroforestry Research Station. Stephanie Gagliardi provided

518 research assistance in the field and laboratory. Two anonymous reviewers provided many

519 excellent comments that improved the quality of this manuscript. Funding for this project

520 was from Agriculture and Agri-Food Canada's Greenhouse Gases Program, the Faculty

521 of Forestry at the University of Toronto, and a Natural Sciences and Engineering

522 Research Council of Canada (NSERC) Discovery Grant to MEI.

\section{References}


525 Bambrick AD, Whalen JK, Bradley RL, Cogliastro A, Gordon AM, Olivier A,

526 Thevathasan N V. (2010) Spatial heterogeneity of soil organic carbon in tree-based

527 intercropping systems in Quebec and Ontario, Canada. Agrofor Syst 79:343-353

528 Bardgett RD, Mommer L, De Vries FT (2014) Going underground: root traits as drivers

529 of ecosystem processes. Trends Ecol Evol 29:692-699

530 Barton CVM, Montagu KD (2004) Detection of tree roots and determination of root

531 diameters by ground penetrating radar under optimal conditions. Tree Physiol

$532 \quad 24: 1323-1331$

533 Bergeron M, Lacombe S, Bradley RL, Whalen J, Cogliastro A, Jutras M-F, Arp P. (2011)

$534 \quad$ Reduced soil nutrient leaching following the establishment of tree-based

535 intercropping systems in eastern Canada. Agrofor Syst 83:321-330

536 Bolte A, Villanueva I (2006) Interspecific competition impacts on the morphology and

537 distribution of fine roots in European beech (Fagus sylvatica L.) and Norway

$538 \quad$ spruce (Picea abies (L.) Karst.). Eur J For Res 125:15-26

539 Borden KA, Isaac ME, Thevathasan NV, Gordon AM, Thomas SC (2014) Estimating

$540 \quad$ coarse root biomass with ground penetrating radar in a tree-based intercropping

$541 \quad$ system. Agrofor Syst 88:657-669

542 Bouttier L, Paquette A, Messier C, Rivest D, Olivier A, Cogliastro A (2014) Vertical root

543 separation and light interception in a temperate tree-based intercropping system of

$544 \quad$ Eastern Canada. Agrofor Syst 88:693-706

545 Burns RM, Honkala BH (1990) Silvics of North America: 1. Conifers; 2. Hardwoods.

546 Agriculture Handbook 654. U.S. Department of Agriculture, Forest Service,

547 Washington, DC. pp. 877 
548 Butnor JR, Doolittle JA, Kress L, Cohen S, Johnsen KH (2001) Use of ground-

549 penetrating radar to study tree roots in the southeastern United States. Tree Physiol

$550 \quad 21: 1269-1278$

551 Canadell J, Jackson RB, Ehleringer JB, Mooney HA., Sala OE, Schulze E-D (1996)

552 Maximum rooting depth of vegetation types at the global scale. Oecologia 108:583-

$553 \quad 595$

554 Cannell MGR, Van Noordwijk M, Ong CK (1996) The central agroforestry hypothesis:

555 the trees must acquire resources that the crop would not otherwise acquire. Agrofor

$556 \quad$ Syst $34: 27-31$

557 Cardinael R, Mao Z, Prieto I, Stokes A, Dupraz C, Kim JH, Jourdan C (2015)

558 Competition with winter crops induces deeper rooting of walnut trees in a

559 Mediterranean alley cropping agroforestry system. Plant Soil 391:219-235

560 Casper BB, Jackson RB (1997) Plant Competition Underground. Annu Rev Ecol Syst $561 \quad 28: 545-570$.

562 Clinch RL, Thevathasan NV, Gordon AM, Volk TA, Sidders D (2009) Biophysical

563 interactions in a short rotation willow intercropping system in southern Ontario,

$564 \quad$ Canada. Agric Ecosyst Environ 131:61-69

565 Dannoura M, Hirano Y, Igarashi T, Ishii M, Aono K, Yamase K, Kanazawa Y (2008)

566 Detection of Cryptomeria japonica roots with ground penetrating radar. Plant

$567 \quad$ Biosyst 142:375-380

568 Das DKK, Chaturvedi OPP (2008) Root biomass and distribution of five agroforestry tree $569 \quad$ species. Agrofor Syst 74:223-230 
570 Day FP, Schroeder RE, Stover DB, Brown ALP, Butnor JR, Dilustro J, Hungate BA, 571 Dijkstra P, Duval BD, Seiler TJ, Drake BG, Hinkle CR (2013) The effects of $11 \mathrm{yr}$ 572 of $\mathrm{CO}_{2}$ enrichment on roots in a Florida scrub-oak ecosystem. New Phytol 200:778$573 \quad 787$

574 Dougherty MC, Thevathasan NV, Gordon AM, Lee H, Kort J (2009) Nitrate and

575 Escherichia coli NAR analysis in tile drain effluent from a mixed tree intercrop and 576 monocrop system. Agric Ecosyst Environ 131:77-84

577 Gale MR, Grigal DF (1987) Vertical root distributions of northern tree species in relation 578 to successional status. Can J For Res 17:829-834

579 Gillespie AR, Jose S, Mengel DB, Hoover WL, Pope PE, Seifert JR, Biehle DJ, Stall T, 580 Benjamin TJ (2000) Defining competition vectors in a temperate alley cropping system in the midwestern USA 1. Production physiology. Agrofor Syst 48:25-40.

582 Guo L, Chen J, Cui X, Fan B, Lin H (2013) Application of ground penetrating radar for 583 coarse root detection and quantification: a review. Plant Soil 362:1-23

584 Guo L, Wu Y, Chen J, Hirano Y, Tanikawa T, Li W, Cui X (2015) Calibrating the impact 585 of root orientation on root quantification using ground-penetrating radar. Plant Soil 289-305

587 Gwenzi W, Veneklaas EJ, Holmes KW, Bleby TM, Phillips IR, Hinz C (2011) Spatial analysis of fine root distribution on a recently constructed ecosystem in a water-

590 Hirano Y, Dannoura M, Aono K, Igarashi T, Ishii M, Yamase K, Makita N, Kanazawa Y 591 (2009) Limiting factors in the detection of tree roots using ground-penetrating 592 radar. Plant Soil 319:15-24 
593 Hirano Y, Yamamoto R, Dannoura M, Aono K, Igarashi T, Ishii M, Yamase K, Makita

594 N, Kanazawa Y (2012) Detection frequency of Pinus thunbergii roots by ground-

595 penetrating radar is related to root biomass. Plant Soil 360:363-373

596 Isaac ME, Anglaaere LCN, Borden K, Adu-Bredu S (2014) Intraspecific root plasticity in

597 agroforestry systems across edaphic conditions. Agric Ecosyst Environ 185:16-23

598 Isaac ME, Anglaaere LCN (2013) An in situ approach to detect tree root ecology: linking

599 ground-penetrating radar imaging to isotope-derived water acquisition zones. Ecol

$600 \quad$ Evol 3:1330-1339

601 Jackson RB, Canadell J, Ehleringer JR, Mooney HA, Sala OE, Schulze ED (1996) A

602 global analysis of root distributions for terrestrial biomes. Oecologia 108:389-411

603 Jayawickreme DH, Jobbágy EG, Jackson RB (2013) Geophysical subsurface imaging for

604 ecological applications. New Phytol 201:1170-1175

605 Jose S, Gillespie AR, Seifert JR, Pope PE (2001) Comparison of minirhizotron and soil

606 core methods for quantifying root biomass in a temperate alley cropping system.

$607 \quad$ Agrofor Syst 52:161-168

608 Li W, Cui X, Guo L, Chen J, Chen X, Cao X (2016) Tree Root Automatic Recognition in

609 Ground Penetrating Radar Profiles Based on Randomized Hough Transform.

$610 \quad$ Remote Sens 8:430

611 Link C, Thevathasan NV, Gordon AM, Isaac ME (2015) Determining tree water

612 acquisition zones with stable isotopes in a temperate tree-based intercropping

$613 \quad$ system. Agrofor Syst 89:611-620 
614 Livesley SJ, Stacey CL, Gregory PJ, Buresh RJ (1999) Sieve size effects on root length

615 and biomass measurements of maize (Zea mays) and Grevillea robusta. Plant Soil

$616 \quad 207: 183-193$

617 Livesley SJ, Gregory PJ, Buresh RJ (2000) Competition in tree row agroforestry systems.

618 1. Distribution and dynamics of fine root length and biomass. Plant Soil 227:149-

$619 \quad 161$

620 Malamy JE (2005) Intrinsic and environmental response pathways that regulate root

$621 \quad$ system architecture. Plant Cell Environ 28:67-77

622 Miller AW, Pallardy SG (2001) Resource competition across the crop-tree interface in a

623 maize-silver maple temperate alley cropping stand in Missouri. Agrofor Syst

$624 \quad 53: 247-259$

625 Mulia R, Dupraz C (2006) Unusual fine root distributions of two deciduous tree Species

626 in southern France: What consequences for modelling of tree root dynamics? Plant

$627 \quad$ Soil 281:71-85

628 Nasielski J, Furze JR, Tan J, Bargaz A, Thevathasan NV, Isaac ME (2015) Agroforestry

629 promotes soybean yield stability and N2-fixation under water stress. Agron Sustain

$630 \quad$ Dev 35

631 Van Noordwijk M, Purnomosidhi P (1995) Root architecture in relation to tree-soil-crop

632 interactions and shoot pruning in agroforestry. Agrofor Syst 30:161-173

633 Oelbermann M, Voroney RP (2007) Carbon and nitrogen in a temperate agroforestry

634 system: Using stable isotopes as a tool to understand soil dynamics. Ecol Eng

$635 \quad 29: 342-349$ 
636 Ong CK, Corlett JE, Singh RP, Black CR (1991) Above and below ground interactions in 637 agroforestry systems. For Ecol Manage 45:45-57

638 Pérez-Harguindeguy N, Diaz S, Garnier E, Lavorel S, Poorter H, Jaureguiberry P, Bret639 Harte MS, Cornwell WK, Craine JM, Gurvich DE, Urcelay C, Veneklass EJ, Reich 640 PB, Poorter L, Wright IJ, Ray P, Enrico L, Pausas JG, de Vos AC, Buchmann N, 641 Funes G, Quétier F, Hodgson JG, Thompson K, Morgan HD, ter Steege H, van der 642 Heijden MGA, Sack L, Blonder B, Poschlod P, Vaieretti MV, Conti G, Staver AC, 643 Aquino S, Cornelissen JHC (2013) New Handbook for standardized measurement 644 of plant functional traits worldwide. Aust J Bot 61:167-234

645 Plante PM, Rivest D, Vézina A, Vanasse A (2014) Root distribution of different mature 646 tree species growing on contrasting textured soils in temperate windbreaks. Plant Soil 380:429-439

648 Prieto I, Roumet C, Cardinael R, Dupraz C, Jourdan C, Kim JH, Maeght JL, Mao Z, 649 Portillo N, Roupsard O, Thammachacksa C, Stokes A (2015) Root functional 650 parameters along a land-use gradient: evidence of a community-level economics $651 \quad$ spectrum. J Ecol 103:361-373

652 Puhe J (2003) Growth and development of the root system of Norway spruce (Picea $653 \quad$ abies) in forest stands: a review. For Ecol Manage 175:253-273

654 Raz-Yaseef N, Koteen L, Baldocchi DD (2013) Coarse root distribution of a semi-arid 655 oak savanna estimated with ground penetrating radar. J Geophys Res $656 \quad$ Biogeosciences 118:135-147

657 Reynolds PE, Simpson JA., Thevathasan NV, Gordon AM (2007) Effects of tree 658 competition on corn and soybean photosynthesis, growth, and yield in a temperate 
tree-based agroforestry intercropping system in southern Ontario, Canada. Ecol Eng $29: 362-371$

661 Schenk HJ, Jackson RB (2002) The Global Biogeography of Roots. Ecol Monogr 72:311$662 \quad 328$

663 Schroth G (1999) A review of belowground interactions in agroforestry, focusing on

664 mechanisms and management options. Agrofor Syst 43:5-34

665 Schwendenmann L, Veldkamp E, Moser G, Hölscher D, Köhler M, Clough Y, Anas I,

666 Djajakirana G, Erasmi S, Hertel D, Leitner D, Leuschner C, Michalzik B, Propastin

667 P, Tjoa A, Tscharntke T, van Straaten O (2010) Effects of an experimental drought

668 on the functioning of a cacao agroforestry system, Sulawesi, Indonesia. Glob

669 Chang Biol 16:1515-1530

670 Stokes A, Fourcaud T, Hruska J, Cermak J, Nadyezdhina N, Nadyezhdin V, Praus L

671 (2002) An evaluation of different methods to investigate root system architecture of

672 urban trees in situ: I. Ground-penetrating radar. J Arboric 28:2-10

673 Stone EL, Kalisz PJ (1991) On the maximum extent of tree roots. For Ecol Manage

$674 \quad 46: 59-102$

675 Thevathasan NV, Gordon AM (2004) Ecology of tree intercropping systems in the North

676 temperate region: Experiences from southern Ontario, Canada. Agrofor Syst

$677 \quad 61: 257-268$

678 Upson MA, Burgess PJ (2013) Soil organic carbon and root distribution in a temperate

679 arable agroforestry system. Plant Soil 373:43-58 
680 Warren JM, Hanson PJ, Iversen CM, Kumar J, Walker AP, Wullschleger SD (2015) Root

681 structural and functional dynamics in terrestrial biosphere models - evaluation and

682 recommendations. New Phytol 205:59-78

683 Wotherspoon A, Thevathasan NV, Gordon AM, Voroney RP (2014) Carbon

684 sequestration potential of five tree species in a 25 -year-old temperate tree-based

685 intercropping system in southern Ontario, Canada. Agrofor Syst 88:631-643

686 Wu Y, Guo L, Cui X, Chen J, Cao X, Lin H (2014) Ground-penetrating radar-based

687 automatic reconstruction of three-dimensional coarse root system architecture.

$688 \quad$ Plant Soil 383:155-172

689 Yan H, Dong X, Feng G, Zhang S, Mucciardi A. (2013) Coarse root spatial distribution

690 determined using a ground-penetrating radar technique in a subtropical evergreen

691 broad-leaved forest, China. Sci China Life Sci 56:1038-1046

692 Zhang C, Li C, Luo G, Chen X (2013) Modeling plant structure and its impacts on carbon

693 and water cycles of the Central Asian arid ecosystem in the context of climate

$694 \quad$ change. Ecol Modell 267:158-179

695

696 Figure captions

697

698

699

700 

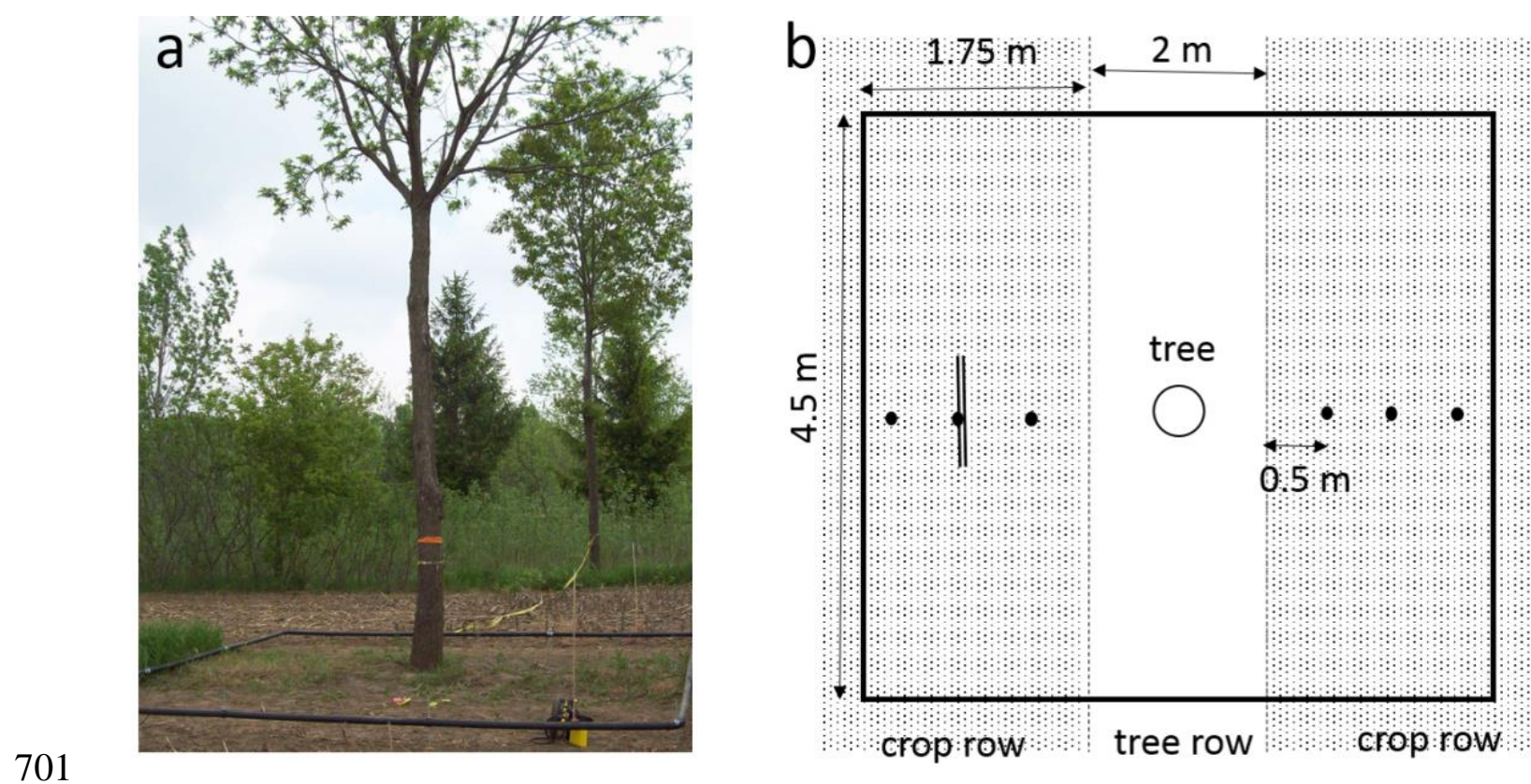

702 Figure 1: Study design for tree root study in a TBI system at the University of Guelph

703 Agroforestry Research Station, Canada. The survey area $(4.5 \times 4.5 \mathrm{~m})$ was centered on

704 each study tree and subsurface data were collected using ground penetrating radar,

705 pictured here for Quercus rubra (a). Ninety-two GPR transects were collected within

706 each survey area, outlined in black, and accuracy of root detection was assessed at

707 exposed $1 \mathrm{~m}$ wide soil profiles, indicated by the solid double line (b). To assess the zone

708 of competition with crops, coarse roots detected by GPR were isolated for those only

709 under the crop rows and fine roots were collected at multiple depths distances, indicated by solid black circles (b) 


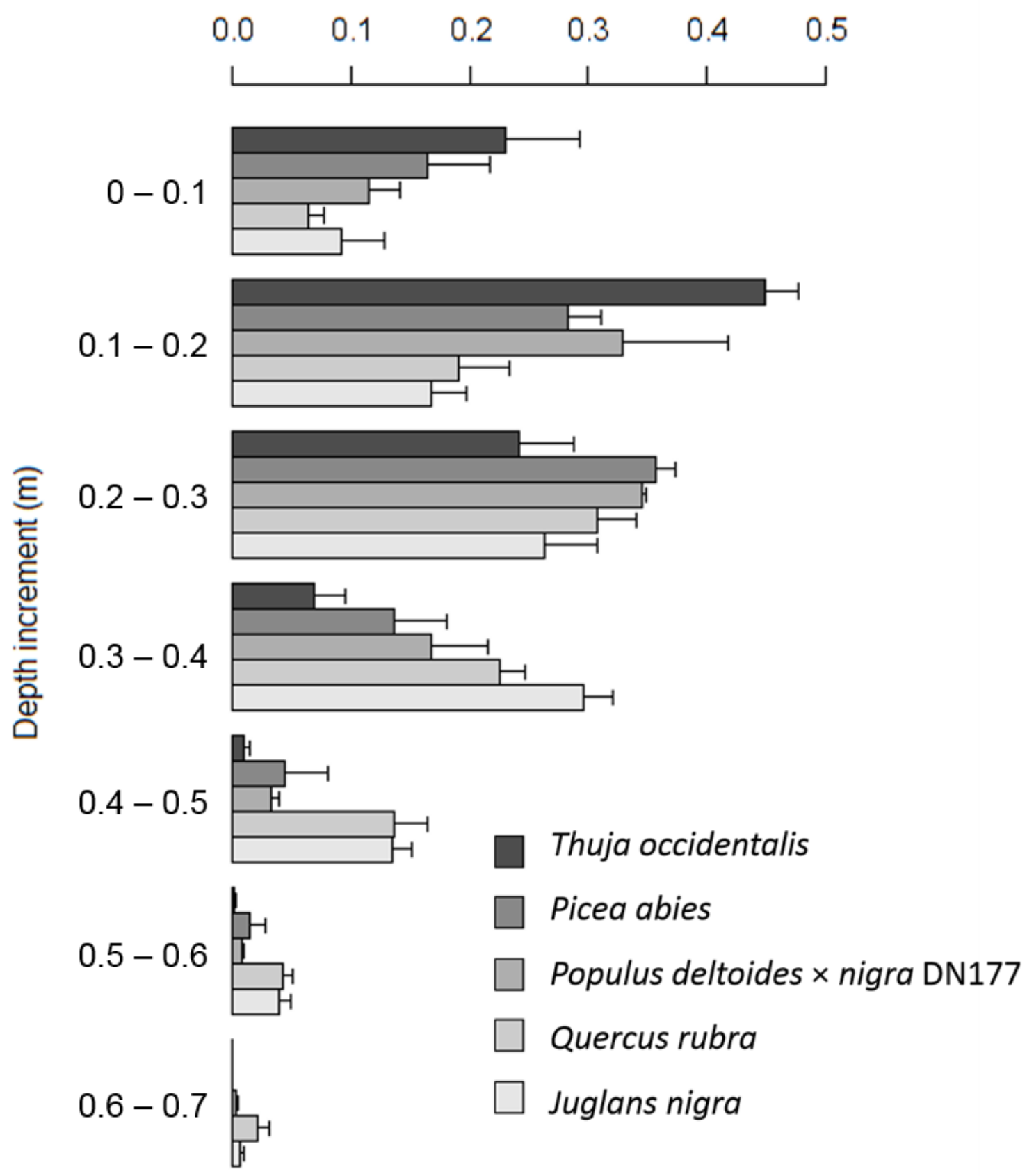

715 Figure 2: Mean GPR-detected coarse roots by $0.10 \mathrm{~m}$ depth intervals for each species

716 ( $n=3$, except Populus sp. and Picea abies $n=2)$. Bars represent standard error of the mean 


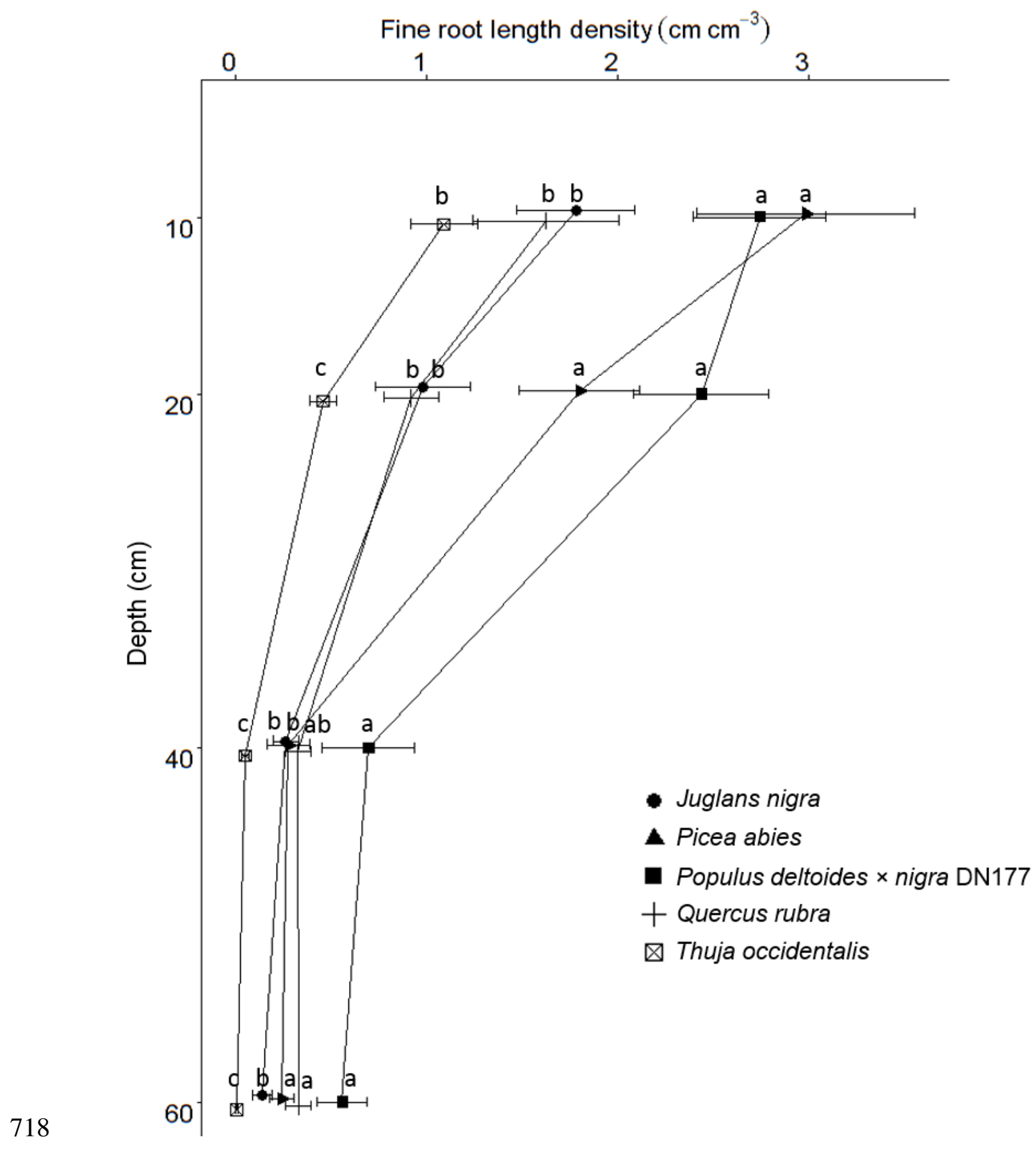

720 Figure 3: Fine root length density (FRLD; $\mathrm{cm} \mathrm{cm}^{-3}$; mean \pm S.E.) at four sampling depths in

721 crop rows ( $n=18$ except $n=12$ for Populus. sp. and P. abies). Comparisons are made across

722 five tree species in a temperate TBI system. Same letters represent non-significant 
723 differences among species at each sampling depth using non-parametric multiple

724 comparisons with Kruskal-Wallis test $(p<0.05)$

725

726

727

728

729

730

731

732

733

734

735

736

737

738

739

740

741

742

743 
745 Table 1: Distribution of coarse roots of five temperate tree species in a TBI system. Summary statistics (mean \pm S.E.) of coarse roots

746 detected by GPR followed by the cumulative root distribution coefficient $(\beta)$ from the equation $\mathrm{Y}=1-\beta^{\mathrm{D}}$ and resulting projected

747 depth of $95 \%$ of roots (D95) are shown

\begin{tabular}{|c|c|c|c|c|}
\hline \multirow[b]{2}{*}{ Species } & \multicolumn{2}{|c|}{ Depth of coarse roots detected by GPR } & \multicolumn{2}{|c|}{ Modelled root distribution } \\
\hline & Mean $(\mathrm{m})$ & Skewness & $\beta$ & $\mathrm{D}_{95}(\mathrm{~m})$ \\
\hline Thuja occidentalis & $0.17 \pm 0.02 \mathrm{a}$ & $0.65 \pm 0.15$ & 0.944 & 0.52 \\
\hline Picea abies & $0.21 \pm 0.02 \mathrm{a}$ & $0.43 \pm 0.08$ & 0.958 & 0.70 \\
\hline Populus deltoides $\times$ nigra DN177 & $0.22 \pm 0.01 \mathrm{ab}$ & $0.68 \pm 0.19$ & 0.958 & 0.70 \\
\hline Quercus rubra & $0.29 \pm 0.02 b$ & $0.44 \pm 0.04$ & 0.969 & 0.95 \\
\hline Juglans nigra & $0.29 \pm 0.01 b$ & $0.21 \pm 0.16$ & 0.969 & 0.95 \\
\hline
\end{tabular}

748 Letters following values within parameter sections represent statistically significant differences in the same column among the tree

749 species (Tukey’s test, $p<0.05, n=3$, except $n=2$ for Populus sp. and $P$. abies)

750

751

752

753 
754 Table 2: Distribution of coarse roots detected within the zone of competition ( $2 \mathrm{~m}$ into crop row). Summary statistics (mean \pm S.E.) of

755 coarse roots detected by GPR followed by the cumulative root distribution coefficient $(\beta)$ from the equation $\mathrm{Y}=1-\beta^{\mathrm{D}}$ and resulting

756 projected depth of $95 \%$ of roots (D95) are shown. These data represent of subset of total tree root system data presented in Table 1 but

757 are isolated for their location in the crop rows

\begin{tabular}{|c|c|c|c|c|}
\hline \multirow[b]{2}{*}{ Species } & \multicolumn{2}{|c|}{$\begin{array}{c}\text { Depth of coarse roots detected by GPR } \\
\text { in crop row }\end{array}$} & \multicolumn{2}{|c|}{$\begin{array}{l}\text { Modelled root distribution } \\
\text { in crop row }\end{array}$} \\
\hline & Mean $(\mathrm{m})$ & Skewness & $\beta$ & $\mathrm{D}_{95}(\mathrm{~m})$ \\
\hline Thuja occidentalis & $0.18 \pm 0.03 \mathrm{a}$ & $0.26 \pm 0.55$ & 0.946 & 0.54 \\
\hline Populus deltoides $\times$ nigra DN177 & $0.22 \pm 0.03 \mathrm{ab}$ & $0.58 \pm 0.00$ & 0.961 & 0.74 \\
\hline
\end{tabular}

758 Letters following values within parameter sections represent statistically significant differences in the same column among the tree

759 species (Tukey's test, $p<0.05, n=3$, except $n=2$ for Populus sp. and P. abies

760 